\title{
Risks, opportunities, and adaptation to climate change
}

\author{
J oel D. Scheraga*, Anne E. G rambsch
}

U.S. Environmental Protection Agency, Mail Code 8601-D, 401 M Street, S.W., Washington, DC 20460, USA

\begin{abstract}
Adaptation is an important approach for protecting human health, ecosystems, and economic systems from the risks posed by climate variability and change, and for exploiting beneficial opportunities provided by a changing climate. This paper presents 9 fundamenal principles that should be considered when designing adaptation policy, for example, a sound understanding of the potential regional effects of climate on human and ecological systems is required to target appropriate investments in adaptive responses. The distribution of potential impacts across different populations and the mechanisms by which these impacts occur are also key to effective adaptation measures. Options for coping with climatic changes must be considered in the context of multiple stressors. Further, adaptation is likely to exhibit varying levels of effectiveness as demonstrated by current efforts to deal with climate variability. Potential adverse side effects of adaptive strategies must also be accounted for to avoid solutions that are worse than the problem. These issues and others are presented in this paper, with examples from various impacts studies to illustrate key points.
\end{abstract}

KEY WORDS: Adaptation · Climate change · Climate variability · Risks · Policy

\section{INTRODUCTION}

Climate variability and change pose risks to human health, ecosystems, social and cultural systems, and economic systems. They also provide opportunities. The goal of climate policy should be to reduce the risks and take advantage of the opportunities. To accomplish this goal, a portfolio consisting of strategies both to mitigate emissions of greenhouse gases and to adapt to change should be considered.

The mitigation of greenhouse gases provides a mechanism for slowing, and perhaps eventually halting, the buildup of greenhouse gases in the atmosphere. As noted in the Intergovernmental Panel on Climate Change (IPCC) 1995 Second Assessment, 'With the growth in atmospheric concentrations of greenhouse gases, interference with the climate system will grow in magnitude, and the likelihood of adverse impacts from climate change that could be judged dangerous will become greater' (IPCC 1996c). Further, the potential for unexpected, large and rapid climate changes ('surprises') may increase due to the nonlinear nature of the climate system. An understanding

*E-mail: scheraga.joel@epa.gov of the potential consequences of climate variability and change - the so-called 'consequences of inaction'provides insights into the appropriate magnitude and rate of implementation of actions to mitigate greenhouse gas emissions.

Adaptation is an important approach for protecting human health, ecosystems, and economic systems, and for maximizing social well-being (NAS 1992). Adaptive actions are those responses or actions taken to enhance the resilience of vulnerable systems, thereby reducing damages to human and natural systems from climate change and variability. While there is uncertainty about future climatic changes, failure to invest in adaptation may leave a nation poorly prepared to cope with adverse changes and increases the probability of severe consequences (Smith \& Lenhart 1996). Adaptive adjustments in practices, processes, or structures of systems will be needed either to reduce the sensitivity of systems to changes in climatic conditions or to exploit new opportunities. ${ }^{1}$ The actions may be taken

\footnotetext{
${ }^{1}$ The extent to which climate change may damage or harm a system is called its vulnerability. It depends not only on a system's sensitivity but also on its ability to adapt to new climatic conditions
} 
in reaction to climate change as it occurs (i.e. reactive adaptation) or in anticipation of future climate change (i.e. anticipatory adaptation).

The climate has changed, is changing, and will continue to change regardless of what investments in mitigation are made (IPCC 1996a). Some of this change will occur as the result of natural climatic variation. Some will occur as the result of human activities that have already altered the atmosphere and committed us to future climate change. Regardless of the source of change, systems that are sensitive to changes in climatic conditions will be affected.

As illustrated in Fig. 1, global average temperature has increased 0.3 to $0.6^{\circ} \mathrm{C}$ over the past $100 \mathrm{yr}$. Global average precipitation over land has increased $1 \%$ during the 20th century, and average sea level has risen 10 to $25 \mathrm{~cm}$ (IPCC 1996a). The character of rainfall also may be changing. For example, the area of the United States that has been affected by extreme rainfall events (i.e. at least $5 \mathrm{~cm} \mathrm{~d}^{-1}$ ) has gone up (Karl et al. 1996). These observed changes led the IPCC to conclude that 'The balance of evidence suggests a discernible human influence on global climate'. However, while some of the observed change in climate during the past $100 \mathrm{yr}$ was likely due to human activities, it is not yet possible to say how much of the change was human-induced.

It is expected that the climate will continue to change as a result of both natural climatic variation and human activities. The IPCC stated that global average temperature is projected to increase another $2^{\circ} \mathrm{C}$ (with a range of uncertainty from 1.0 to $3.5^{\circ} \mathrm{C}$ ) by the year 2100 as a result of both human and natural influences (IPCC 1996a). Global average precipitation is likely to continue to rise as the hydrologic cycle intensifies, with a possibility of more extreme rainfall events. Average sea level will rise another $50 \mathrm{~cm}$ (with a range of uncertainty from 15 to $97 \mathrm{~cm}$ ) by 2100 .

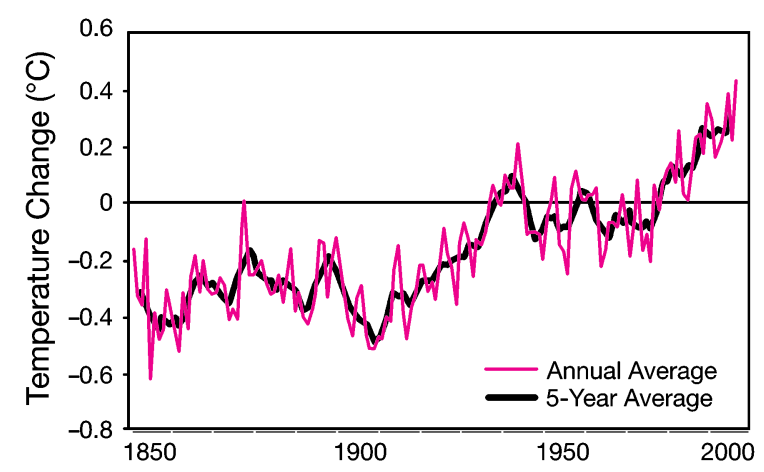

Fig. 1. Combined land-surface air and sea surface temperatures from 1851 to 1997, relative to 1961-1990 (J ones 1994 [land], Parker et al. 1995 [marine])
Changes in climate are of concern because there are a variety of systems that are sensitive to climate, including human health, ecosystems, and socioeconomic systems (IPCC 1996b, 1997, Scheraga 1998). While it is impossible to attribute any single climatic event to human-induced climate change, as opposed to natural climatic variation (e.g. the Kansas drought from 1952 to 1957; the 1993 M issouri and M ississippi River floods; the 1995 Chicago heat wave and the 1998 Dallas heat wave), they highlight potential vulnerabilities to climate and our ability, or inability, to cope with such changes. As the climate continues to change, our ability to protect these sensitive systems may be further challenged. In addition, the possibility of abrupt climatic 'surprises' cannot be discounted. In these cases, waiting to react to climate change may be unsatisfactory because the adverse effects of climate change may be significant (OTA 1993). It is therefore prudent to begin considering investments in adaptive responses to reduce the vulnerability of human health, ecosystems, and socioeconomic systems to current climate variability and future climate change.

The purpose of this paper is to present 9 fundamental issues pertaining to the effective design of adaptation policy and to demonstrate the importance of understanding the potential consequences of climate variability and change for ensuring the effectiveness of adaptive responses. A sound understanding of the potential effects of climate on human and ecological systems is a prerequisite for targeting appropriate investments in adaptation. The characteristics of potential impacts, including their distribution across different populations and geographic regions, and the mechanisms by which the impacts occur are also key to effective adaptation measures and must be investigated thoroughly. Finally, potential side effects of the adaptive strategies must be accounted for to avoid maladaptation, i.e. a 'cure' that is worse than the 'disease'.

\section{FUNDAMENTAL PRINCIPLES}

Only society can decide whether or not particular risks and opportunities are of concern. The extent to which society is willing to expend resources to avoid the effects of climate change will depend in part on its perceptions of the risks posed by climate change, the perceived costs of the effort, and how much it is willing to risk possible negative consequences (NAS 1992, OTA 1993). If society decides to adapt, important issues must be considered to ensure that the adaptive responses are effective. We present, with examples, 9 fundamental principles that should be considered when designing adaptation policy: 
(1) The effects of climate change vary by region.

(2) The effects of climate change may vary across demographic groups.

(3) Climate change poses risks and opportunities.

(4) The effects of climate change must be considered in the context of multiple stressors and factors, which may be as important to the design of adaptive responses as the sensitivity to change.

(5) Adaptation comes at a cost.

(6) Adaptive responses vary in effectiveness, as demonstrated by current efforts to cope with climate variability.

(7) The systemic nature of climate impacts complicates the development of adaptation policy.

(8) Maladaptation can result in negative effects that are as serious as the climate-induced effects being avoided.

(9) Many opportunities for adaptation make sense whether or not the effects of climate change are realized.

\subsection{The effects of climate change vary by region}

There is a regional texture to changes in climate, and therefore to the effects of climate change (Shriner \& Street 1997, Scheraga 1998). Although global average temperatures have increased 0.3 to $0.6^{\circ} \mathrm{C}$ and global average precipitation levels have increased $1 \%$ during the past $100 \mathrm{yr}$, there has been significant regional variation in these changes (Fig. 2). There has been as much as a $3^{\circ} \mathrm{C}$ increase in average temperatures in some parts of the United States, such as North Dakota and Oregon. But in other locations, such as Georgia and $\mathrm{M}$ ississippi, average temperatures have decreased as much as $3^{\circ} \mathrm{C}$. There has been as much as a $20 \%$

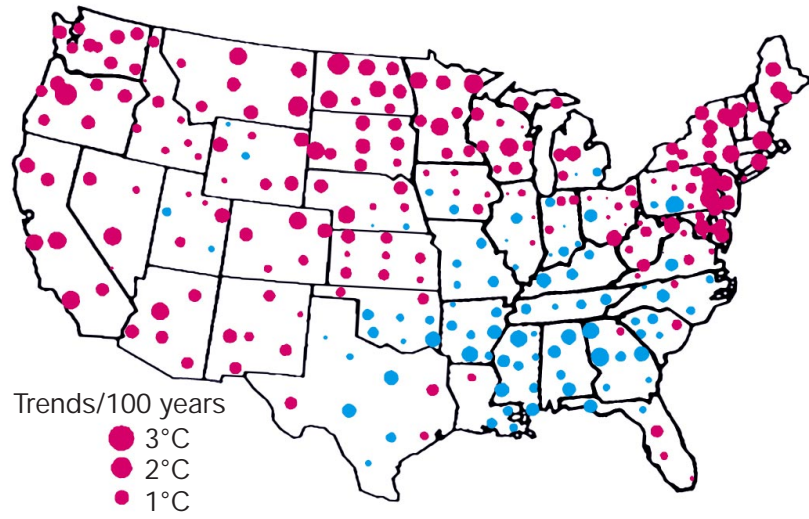

Fig. 2. Coterminous United States temperature trends for 1900 to 1994 (converted to ${ }^{\circ} \mathrm{C}$ century ${ }^{-1}$ ), centered within state climatic divisions. Trend magnitude is reflected by the diameter of the circle. Red circles represent increases and blue circles represent decreases (Karl et al. 1996) increase in the mean level of precipitation in some parts of the country, such as the Susquehanna River Basin, northeast USA and New Mexico. But in other locations, such as California and Wyoming, the mean level of precipitation has decreased by as much as $20 \%$ (Karl et al. 1996).

In the same way that there is a regional texture to ongoing climate change, there is a regional texture to the risks and opportunities presented by climate change. The human and ecological systems that are sensitive to climate change, and the degree to which they are vulnerable, will vary geographically. This variation must be considered as adaptive strategies are developed.

An examination of the agriculture sector illustrates this point. Several studies (Adams et al. 1995a, b, Rosenzweig et al. 1995) suggest that, although United States agriculture may, in the aggregate, benefit from climate change, changes in agricultural yields may vary across regions. Further, as described in the 1997 IPCC Regional Impacts Assessment, climate change impacts on crops will likely result in sub-regional shifts in economic welfare (IPCC 1997). For example, under the climate scenario depicted in Fig. 3, farmers who plant corn in New England may experience increases in yields, but farmers who plant corn in the Great Plains may experience declines in yields. Thus, climate change may pose an opportunity for corn farmers in New England, but a risk for corn farmers in the Great Plains. There also will be differences within regions. Farmers who plant wheat in South Dakota may experience increases in yields, but farmers who plant corn in South Dakota may experience declines in yields. Climate change may pose an opportunity for wheat farmers, but a risk for corn farmers in South Dakota.

Adaptation, especially at the farm level, will be essential for limiting losses due to changing climatic conditions or for taking advantage of these changes (Reilly 1996). Regional information is useful because it can help guide adaptive decisions (e.g. planting dates, planting different crop varieties or species, irrigation, fertilizer use, tillage, etc.) by farmers within a region and across regions.

\subsection{The effects of climate change may vary across demographic groups}

There will be distributional effects across demographic groups as well as across geographic regions. Vulnerable populations will vary, depending upon the effect of climate change being considered. For example, it is known that climate change will likely increase the frequency of very hot days during the summer, and thus the number of deaths due to heat stress may rise 

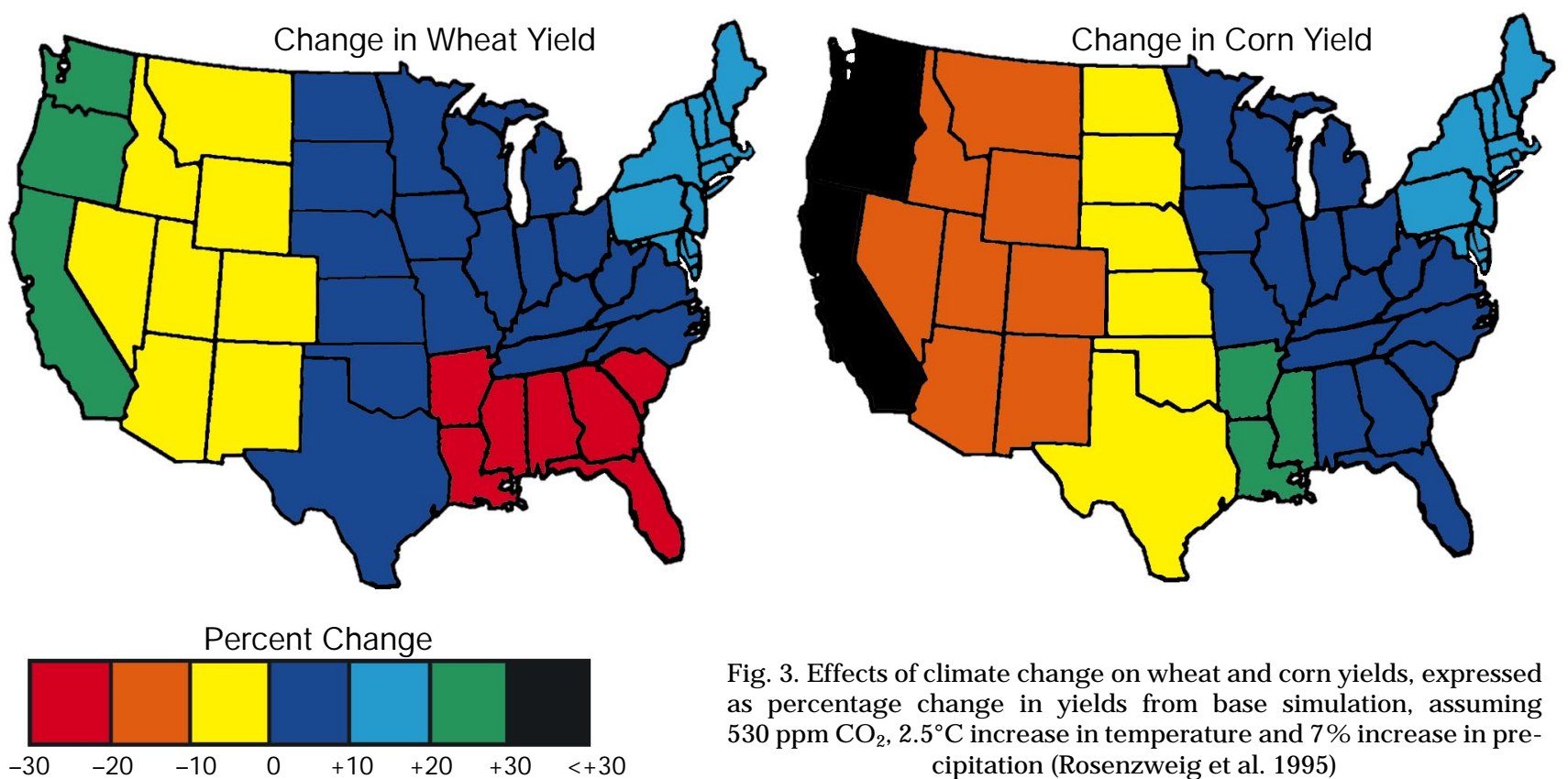

Fig. 3. Effects of climate change on wheat and corn yields, expressed as percentage change in yields from base simulation, assuming $530 \mathrm{ppm} \mathrm{CO}, 2.5^{\circ} \mathrm{C}$ increase in temperature and $7 \%$ increase in precipitation (Rosenzweig et al. 1995)

(Kalkstein \& Greene 1997). As illustrated in Fig. 4, the most vulnerable populations are the elderly (Kilbourne et al. 1982, CDC 1995, Nashold et al. 1996, Semenza et al. 1996). For example, during the 1995 Chicago, USA, heat wave 465 heat-related deaths were recorded, and those $65 \mathrm{yr}$ and older accounted for nearly $70 \%$ of the total (NOAA 1995). The very young are also sensitive to heat. Cities are disproportionately affected by heat, with the urban heat island effect and inner-city poverty being contributing factors (Buechley et al. 1972, Oke 1973).

Acclimatization of populations may reduce the predicted heat-related mortality. People in Montreal and

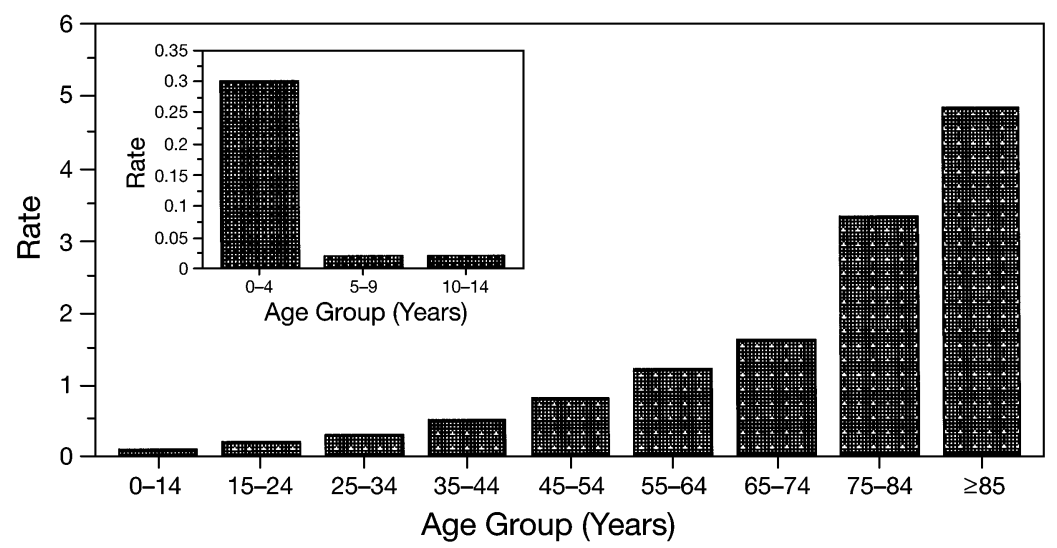

Fig. 4. Average annual rate of heat-related deaths in the United States by age group: 1979 to 1995. Rates are per million population. Underlying cause of death attributed to excess heat exposure classified according to the International Classification of Diseases, Ninth Revision, as code E900.0, 'due to weather conditions' (CDC 1998)
Toronto, Canada, might acclimatize somewhat to global warming conditions, whereas people in Ottawa, Canada, show no signs of potential acclimatization (Kalkstein \& Smoyer 1993). It is important to note that acclimatization to increasing temperatures occurs gradually, particularly among the elderly, and may be slower than the rate of ambient temperature change (Shriner \& Street 1997).

To be effective, adaptive responses must target these vulnerable demographic groups, some of which may be difficult to reach (Chestnut et al. 1998). For example, the elderly are less likely to perceive excess heat (Blum et al. 1998). They may be socially isolated and physically frail (Kilbourne et al. 1982, Semenza et al. 1996). This may make it difficult to get them to use air conditioning (i.e. they do not feel the heat) or to travel to air-conditioned environments (i.e. they have no one to take them and may be unable to travel on their own). The poor may not be able to afford air conditioning, and if they live in high crime areas then they may be afraid to visit cooling shelters. Finally, for young children and infants, decisions about how warmly to dress and time spent in hot environments are made by adults, and they may be unable to communicate their discomfort (Blum et al. 1998). Effective responses will need to take these group-specific factors into account. 


\subsection{Climate change poses risks and opportunities}

M any, but not all, of the systems that are sensitive to current climate and likely to be sensitive to future changes in climate have been identified (Fig. 5). Potential effects on human health, air quality, water quantity and quality, ecosystems (including wildlife and biodiversity), agriculture and forests may be either positive or negative. If the ultimate goal of climate policy is to protect public health and the environment, and increase society's well being, then it is imperative that adaptation policy exploit the potential positive effects of climate change, as well as reduce the risks. 'A lost opportunity can be as bad as a negative impact.' At the same time, any 1 particular effect of climate change may benefit one region or demographic group within a region, while harming another region or demographic group (at least in a $2 \times \mathrm{CO}_{2}$ world). ${ }^{3}$ 'One person's opportunity may be another person's loss.'

${ }^{2}$ Comment by Roger Street at 1998 A \&WM A A nnual M eeting. Session on 'Climate Change II - impacts on N orth America: what do we know?' San Diego, CA, J une 1998

${ }^{3} \mathrm{M}$ ost of the conclusions of this paper are based on analyses of potential consequences of climate change when atmospheric concentrations of $\mathrm{CO}_{2}$ have been doubled (the socalled $2 \times \mathrm{CO}_{2}$ world). However, there is some preliminary evidence that suggests there may be much more severe climatic changes and ensuing impacts as atmospheric concentrations increase to $3 \times \mathrm{CO}_{2}$ and $4 \times \mathrm{CO}_{2}$ ( $\mathrm{M}$ ahlman 1998)
The tradeoffs between opportunities to be exploited and risks to be avoided pose a serious challenge to public policy makers and resource managers. It is noteworthy that, when one considers all impact categories, it is likely that every region and state will be exposed to some risks from climate change, as well as some positive effects.

Consider, for example, potential changes in recreational fishing opportunities that may result as climate change affects habitat for freshwater fish in rivers and streams in the United States (U.S. EPA 1995b). It is well known that fish have thermal tolerance levels that vary by fish species (Eaton et al. 1995). A general increase in surface air temperatures will also increase water temperatures, resulting in changes in habitat suitable for various fish species.

These physical impacts could result in substantial disruptions to an important American pastime, recreational fishing. As reported by the U.S. Department of the Interior (1997), the United States has much at stake in recreational fishing. About $15 \%$ of the United States population $16 \mathrm{yr}$ and older went freshwater fishing in 1996. They spent over 500 million days fishing in freshwater and \$24 billion (1996\$).

Changes in fish habitat will affect the kind of fish that can be caught, the chances of success, the quality of the fishing experience itself, and proximity to the fishing opportunity. All of these factors will affect recreational fishing behavior. Since fishing opportunities

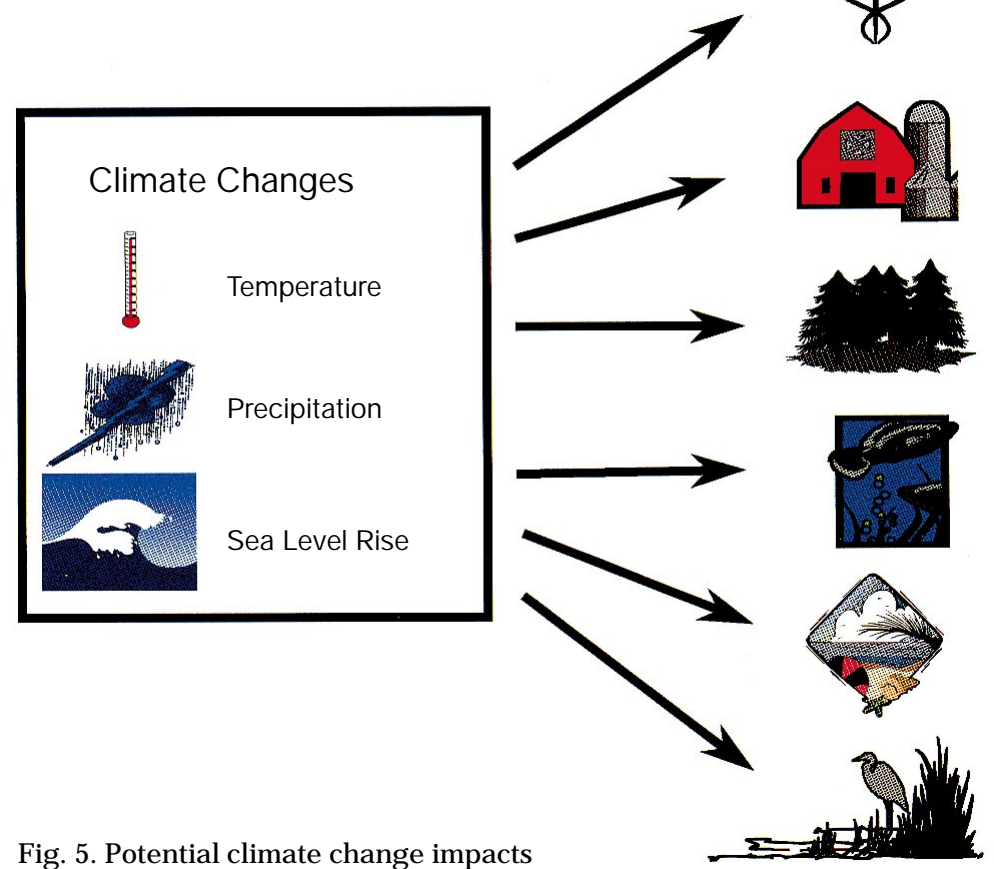

Health Impacts

Weather-related Mortality

Infectious Diseases

Air Quality-Respiratory Illnesses

Agriculture Impacts

Crop yields

Irrigation demands

Forest Impacts

Change in forest composition

Shift geographic range of forests

Forest Health and Productivity

Water Resource Impacts

Changes in water supply

Water quality

Increased competition for water

Impacts on Coastal Areas

Erosion of beaches

Inundation of coastal lands

Costs to defend coastal communities

Species and Natural Areas

Shift in ecological zones

Loss of habitat and species 


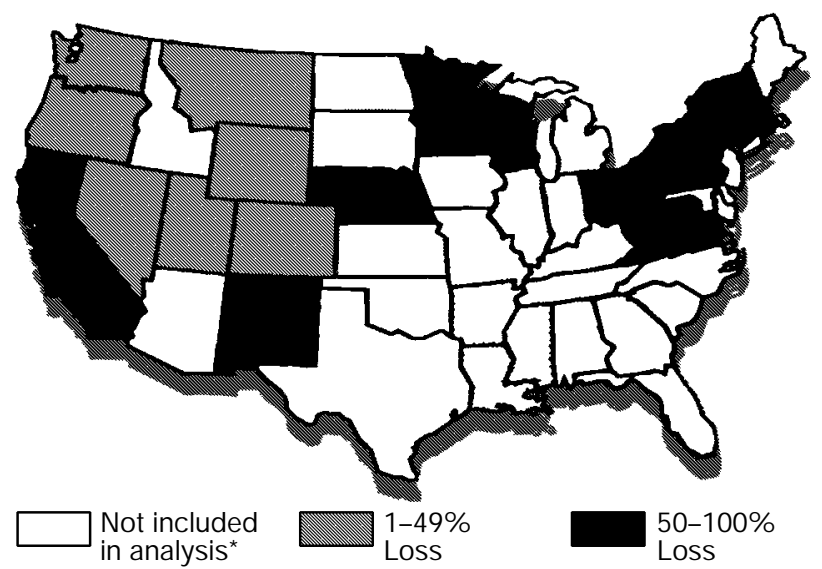

Fig. 6. Loss of habitat for brown trout from a doubling of $\mathrm{CO}_{2}$ by the year 2050. Results shown are for the GFDL model (Manabe \& Wetherald 1987). Screening criteria used for inclusion: (1) thermal modeling predicts suitability, and (2) fish presence in $10 \%$ or more of state's water bodies (U.S. EPA 1995b). *Screening criteria were not met

for the different guilds of fish are valued differently, the physical effects of climate change may result in either losses or opportunities for recreational fishermen.

Fig. 6 illustrates the effects on recreational fishing for one particular transient scenario of climate change developed by the Geophysical Fluid Dynamics Laboratory (GFDL) (Manabe \& Wetherald 1987). Under this GFDL scenario, the habitat for brown trout, which is a coolwater fish, declines from 1 to $100 \%$ in a $2 \times$ $\mathrm{CO}_{2}$ world in every state included in the analysis. However, coolwater, warmwater, or rough fish are likely to move into these streams. These effects will vary by region. ${ }^{4}$

Whether or not these potential changes in fish habitat and recreational fishing opportunities are of concern is for society to decide. But it is important that the range of potential effects, including both risks and opportunities, be articulated for policy makers. To the extent that society chooses to avoid these shifts, investments will have to be made in greenhouse gas mitigation to slow or stop the rate of human-induced climate change. To the extent that the shifts are unavoidable, fishery management strategies or recreational behavior may have to adjust (i.e. adapt) to changes in fish habitat and fish availability.

\footnotetext{
${ }^{4}$ For the GFDL transient 2050 scenario, the net effect is a projected annual loss of $\$ 320$ million (1991 \$) for the 48 contiguous states. This is primarily due to the loss of coolwater acreage. However, for 2 different GFDL and GISS equilibrium scenarios of climate change, gains in cool- and warmwater fishing offset losses in coldwater fishing, resulting in annual benefits of about $\$ 80$ million each
}

\subsection{The effects of climate change must be consid- ered in the context of multiple stressors and factors, which may be as important to the design of adaptive responses as the sensitivity to change}

Many of the systems that are sensitive to climate change and climate variability, such as population growth, land-use changes, and pollution, are already under stress for other reasons. Climate change may exacerbate or ameliorate existing stresses. As a result, any assessment that is concerned with identifying the potential consequences of climate change and developing appropriate adaptive responses must consider 2 questions: (1) What are the existing stresses on human health and ecosystems within a particular region under current climatic conditions? (2) How might climate change exacerbate or ameliorate these stresses?

To illustrate the importance of assessing the potential consequences of climate change within a larger context, consider the potential effect that climate change may have on natural ecosystems. The rate of climate change, the size of species ranges, and the dispersal rates of individuals species all are important determinants of the ability of natural ecosystems to adapt to changing climate conditions and many analyses include these factors. However, existing threats to natural ecosystems and species diversity will also affect ecosystem resiliency and capacity to adapt to climate change. Conversion of land for human activities (e.g. urban settlements, farming, harvesting of forests) can interfere directly with seed dispersal and cause changes in the composition of forested ecosystems. Natural and manmade barriers, such as roads, cities, bodies of water, and agricultural land may block migration of species. Manmade pollution and habitat degradation may impair the health of particular species, making them less able to withstand stresses from climate change. Al pine ecosystems may simply run out of room as alpine temperatures migrate above the mountaintops. Fragmentation of ecosystems and competition from introduced exotic species may make it impossible for species to migrate to suitable areas in response to climatic shifts. Failure to include these stressors will result in an incorrect picture of future ecosystem distributions.

Humans may also indirectly affect ecosystem migration through other activities, such as through the consumption of water that is needed by the ecosystem to survive. Consider that as the climate changes, water supplies will be directly affected by precipitation changes and increased evapotranspiration. The availability of water also will be indirectly affected by changes in the competition for water among multiple uses (e.g. urban water demand, recreational activities, irrigation in agriculture, hydropower). In such cases, 
the water required by natural ecosystems such as forests to survive may become scarcer (e.g. in the Pine Barrens of New J ersey).

A complete assessment of the vulnerability of human health and ecosystems to climate change that correctly identifies possible risks and opportunities must consider the multiple stressors on the affected systems. Assessments that do not include these stressors will provide incorrect information to those who are developing adaptive responses in anticipation of future change, increasing the possibility that less effective adaptation, and in some cases maladaptive strategies, will be chosen. For example, an understanding of the potential fragmentation of forests due to the influence of humans and economic activity is necessary to ensure that effective mechanisms are developed (if society so chooses) to protect forests and the wildlife that inhabit them (e.g. through the development of corridors for seed dispersal and wildlife migration).

\subsection{Adaptation comes at a cost}

Adaptation is not without cost. The scarce natural and financial resources used to adapt to climate change could be used for other productive activities. In the vernacular of economics, there are opportunity costs to using scarce resources for adaptation. These costs must be carefully weighed when considering the tradeoffs among adapting to the change, reducing the cause of the change, and living with the residual impacts (Shriner \& Street 1997). It is imperative that any adaptation policy be economically justified. The discounted benefits of the policy should be greater than its discounted costs (Smith 1997). Economical adaptation that lessens sensitivity to climate is desirable (NAS 1992).

For example, the implementation of any adaptation options to protect shorelines will necessitate significant financial commitments from various countries at risk from sea level rise, although the level of required funding might vary widely from one option to another. In the $\mathrm{M}$ aldives, the present costs of shoreline protection are close to $\$ 13000 \mathrm{~m}^{-1}$. In Senegal, Benin, Antigua, Egypt, Guyana, the Marshall Islands, St. Kitts-Nevis, and Uruguay, maintenance of the existing shoreline against a $1 \mathrm{~m}$ rise in sea level could require substantial funding compared with the nation's GNP (Bijlsma 1996).

In the United States, the projected global average rise in sea level of $50 \mathrm{~cm}$ by 2100 will threaten coastal properties, erode beaches, threaten wetlands and wild life habitat. It could inundate 8600 to $19000 \mathrm{sq} . \mathrm{km}$ of dry land if no shores are protected, and 5700 to 16000 sq. km if currently developed areas are pro- tected (Titus et al. 1991). It is possible to protect developed areas by building bulkheads and levees, pumping sand onto beaches, and raising houses, roadways, and barrier islands. But this protection comes at a significant cost. It has been estimated that for a $50 \mathrm{~cm}$ rise, barrier islands in the United States could be protected at a total cost of $\$ 55$ to 123 billion. This protection would occur by placing sand on eroding beaches and the low bay sides at a cost of $\$ 15$ to 81 billion, elevating houses and roads at a cost of $\$ 29$ to 36 billion, and protecting mainland areas with dikes and bulkheads at a cost of $\$ 5$ to 13 billion (Titus et al. 1991, Shriner \& Street 1997).

Several studies, in particular those on agricultural impacts, only estimate the benefits of adaptation but do not fully account for its cost. However, while climate change impacts will be reduced in a fully adapted society, the process of reaching this level could be costly (Tol et al. 1998). For example, Reilly et al. (1994) estimated global welfare losses to agriculture of $\$ 0.1$ to $\$ 61.2$ billion without adaptation, but that farm-level adaptation can change these figures to between a gain of $\$ 7.0$ and a loss of $\$ 37.6$ billion. However, the costs of adaptation are ignored and are not reported or included in the impact estimates (Tol et al. 1998).

In assessing the potential effectiveness of adaptation, it is imperative that one evaluates the availability of the resources required to implement alternative adaptive strategies. The lack of appropriate technology and trained personnel, financial limitations, cultural and social values, and political and legal institutions may all restrict a nation's ability to implement adaptation measures, which will likely vary across geographic regions and demographic groups. Also, one must evaluate the willingness of society to divert required resources away from other desired uses.

\subsection{A daptive responses vary in effectiveness, as demonstrated by current efforts to cope with climate variability}

In assessing the capacity of society to adapt to climate change in order to project future vulnerabilities, it is instructive to look at the effectiveness of adaptation policy under current climatic conditions. Historic evidence demonstrates that society has not always adapted to existing risks effectively.

For example, exposure to extreme heat causes, on average, up to 270 deaths in the United States even during years with no heat waves. During heat waves, these numbers can increase dramatically. In 1980, 1983, and 1988, for example, substantial numbers of people (1700, 556, and 454 people, respectively) died of the heat (CDC 1995). In July 1995, a heat wave 
caused 465 heat-related deaths in the Chicago area alone (CDC 1995). These are preventable deaths.

There are a wide array of possible explanations for society's failure to adapt effectively to existing risks. As suggested by the earlier discussions, this may be due to a failure to identify and understand stressors and factors that affect the risk and the ability of society and individuals to respond. It may be due to limited resources available to society for adaptation. Or it may be due to a conscious decision by society not to invest scarce resources in adaptive responses. Regardless of the reasons for the limited effectiveness of existing adaptive responses, the historic evidence suggests that one cannot be cavalier about the effectiveness of adaptive strategies when making projections of future vulnerabilities to climate change.

Another reason for being cautious about the effectiveness of adaptive responses to future climate change is the existence of significant scientific uncertainties about future consequences. For example, although the potential implications of climate change for United States agriculture have been extensively studied and adaptation strategies evaluated, potentially significant uncertainties still exist (Reilly 1996). M ost studies have examined the effects of changes in average climate on crop yields, and have not fully accounted for changes in climate variability in new and unprecedented climatic regimes (Tol et al. 1998). The potential effects of climate change on the prevalence of pests, pathogens, and weeds, which may affect crop yields, have not been evaluated. Also, many studies have made strong assumptions about adaptation responses, but have not fully accounted for changes in water availability (which is necessary for irrigation) and the competition for water among various systems and sectors (Shriner \& Street 1997).

\subsection{The systemic nature of climate impacts complicates the development of adaptation policy}

Climate change will have wide-ranging effects. Most of these effects are likely to occur simultaneously. Also, many of the effects are interdependent. The systemic nature of climate change and its effects poses unique challenges to resource managers developing adaptive responses (Shriner \& Street 1997). Sensitive systems cannot be considered independently. An adaptation strategy that may protect one particular system may, inadvertently, increase risks to other systems. In some cases, it may be impossible to avoid all risks and exploit all opportunities. Society may have to choose between alternative outcomes.

For example, if the protection of coastal property from sea level rise were the only concern, sea walls could be built. Along the Chesapeake Bay, $32 \mathrm{~km}$ of bulkheads $\mathrm{yr}^{-1}$ are currently being built to protect coastal property. But the rise in sea level also threatens wetlands, and the building of sea walls prevents new wetlands from forming. The rise in sea levels could drown 15 to $60 \%$ of coastal wetlands in the United States, posing risks to fish, shellfish, flood and erosion control, and habitat (Fig. 7). ${ }^{5}$ Destruction of wetlands can then affect bird migration patterns. Finally, the rise in sea level could also lead to saltwater intrusion, threatening freshwater aquifers and drinking water (e.g. Biscayne aquifer in Florida could become salty with a $92 \mathrm{~cm}$ rise in sea level), and freshwater that is required for other uses (e.g. water for irrigation).

A comprehensive approach must be taken to the development of adaptation strategies to identify possible tradeoffs that society may have to make between future outcomes, reduce risks effectively, exploit opportunities presented by climate change, and maximize social well being.

\subsection{Maladaptation can result in negative effects that are as serious as the climate-induced effects being avoided}

Adaptive responses can also have adverse effects. The previous discussion suggested that an adaptive response that is made without consideration for interdependent systems may, inadvertently, increase risks to other systems that are sensitive to climate change.

\footnotetext{
${ }^{5}$ There will be regional differences in the rise of sea level relative to coastal lands (U.S. EPA, October 1995a). Other factors, such as land subsidence, affect the relative position of the land to the sea
}

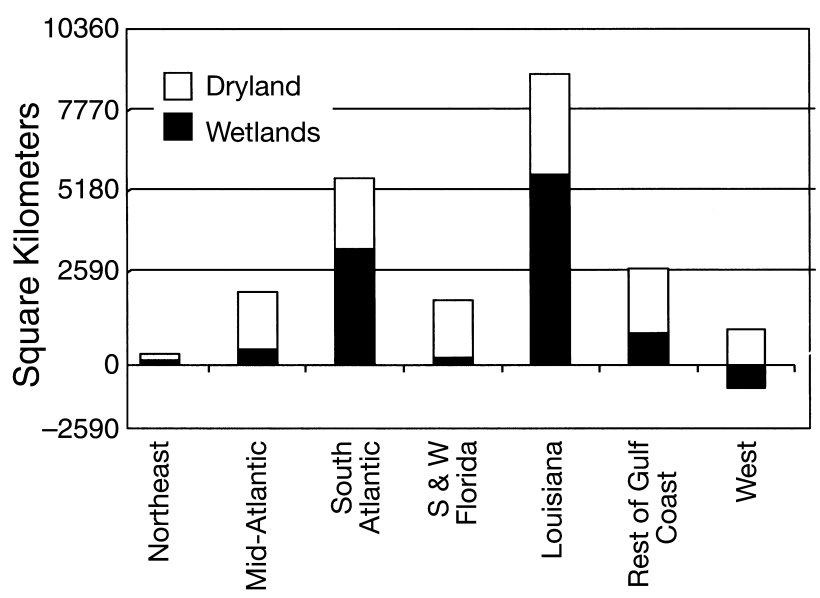

Fig. 7. United States coastal lands at risk from a 20 inch $(\sim 51 \mathrm{~cm})$ sea level rise by 2100 (U.S. EPA 1989) 
However, even when a comprehensive approach is taken to the development of strategies for adapting to climate-induced effects, one must account for potential non-climate related side effects of the adaptive strategies to avoid maladaptation. The possibility has to be considered that adaptive responses might have adverse consequences for human health or the environment (Shriner \& Street 1997, Parry \& Carter 1998). Adaptive responses also might have adverse consequences for social well being. Consideration should be given in the design of adaptive strategies to issues of equity. The social acceptability of a particular adaptive response may depend upon who in society will benefit from the adaptation policy and who will lose (Smith et al. 1995).

The adverse consequences of some adaptive responses for the environment can be illustrated by historic societal responses to sea level rise. The possible responses to inundation, erosion, and flooding due to sea level rise fall into 3 categories: erecting walls to hold back the sea, allowing the sea to advance and adapting to the advance, and raising the land (U.S. EPA 1989). Along most mainland shorelines, economic self-interest would encourage property owners to erect bulkheads. This adaptive response might be effective for protecting coastal property. But the bulkheads would prevent new wetland formation from offsetting the loss of wetlands that were inundated (Titus 1986). Such maladaptive responses are already being undertaken. Coastal property along Chesapeake Bay is being protected through the construction of bulkheads and revetments. Between 1979 and 1994, $161 \mathrm{~km}$ of new bulkheads, $285 \mathrm{~km}$ of new revetments, and $84 \mathrm{~km}$ of replacement bulkheads were constructed (Titus 1998). This construction threatens the survival of wetlands along the shore of Chesapeake Bay.

A second example of potential maladaptation is the response to risks posed by climate change to fisheries. Climate change is likely to exacerbate existing stresses on fish stocks. Hatcheries can be used to enhance natural recruitment of fish stocks when climate causes stocks to fall below the carrying capacity of an ecosystem for a given species. This adaptive response might increase stock productivity, reduce recruitment variability, and enable the colonization or recolonization of new areas. But injudicious use may alter or impoverish the biodiversity of an ecosystem and the genetic pool of resources. It might also lead to the transmission of parasites and diseases (Everett 1996).

A third example of potential maladaptation is the potential response to risks posed by climate change to human health. It will be important to assess in advance the risks to health from some proposed technological adaptations to climate change. Increased use of air conditioning would protect against heat stress, but it also could increase emissions of both greenhouse gases and conventional air pollutants (U.S. EPA 1989, IPCC 1996b). Similarly, available evidence and climate change models indicate that climate change will alter the pattern of the world's infectious diseases. Public health programs should therefore anticipate the health impacts of climate change on infectious disease. One possible adaptive response is the use of pesticides for vector control (WHO 1996). However, the effects of pesticides on human health and insect predators and increased insect resistance to pesticides all need to be considered if new pesticides are used to control disease vectors. New chemicals or treatments for vector control not only need to be effective, but their breakdown products should be non-toxic and non-persistent.

In all of these examples, a well-informed decision maker may decide that the adverse effects of the adaptive measures are of greater concern than the risks posed by climate change itself. It is important that all adaptive responses be evaluated to identify possible adverse consequences and how they might affect the range of feasible and desirable adaptive responses that are available.

\section{9. $M$ any opportunities for adaptation make sense whether or not effects of climate change are realized}

Many strategies that would reduce risks posed by climate change or exploit opportunities make sense whether or not the effects of climate change are realized. Adaptation measures may result in agricultural systems that are more resilient to climate variability (e.g. new crop varieties that are heat- and droughtresistant may reduce crop losses during hot, dry summers today). Enhanced responses to urban heat waves can save lives now.

In other cases, existing institutions and public policies result in systems that are more rigid and unable to respond to changing conditions. For example, the existence of the system of water rights and the absence of competitive markets for water in many western United States has led to an inefficient allocation of water among alternative uses. Implementation of competitive markets would allow more flexibility in allocating water, allocate water to its highest-valued uses, and improve our ability to deal with current variability in water flows, in addition to adapting to future climate stresses. Other policies, such as the existence of federal flood insurance, provide an incentive for development in high-risk coastal areas. Elimination of federal flood insurance would reduce the inventory of private property that is at risk today, as well as in the future when sea level rises further. 
Care must be taken, however, in evaluating such 'no regrets' strategies. These strategies would lead to a more efficient allocation of scarce resources under current and future climatic conditions. However, the formulation of public policies often involve considerations other than efficiency (e.g. equity considerations, political feasibility). These additional considerations must be accounted for in the assessment of 'no regrets' strategies for adapting to climate change.

\section{CONCLUSIONS}

Anticipatory adaptation is a risk management policy. Although many uncertainties exist about the potential consequences of future climate change, existing evidence suggests that the climate is changing and will continue to change. This will result in both beneficial and adverse effects on human health, ecosystems, and economic systems that are sensitive to changes in climate. Investments in adaptation are warranted to reduce the vulnerability of systems to climate change and to exploit opportunities that may increase social well being.

This paper has articulated 9 fundamental issues that should be considered when developing adaptive strategies and evaluating the extent to which they should be relied upon. Taken together, the 9 principles suggest that the development of adaptation policies is a complex undertaking. One should not be cavalier about the ease with which adaptation strategies can be developed, nor about the potential effectiveness of strategies to adapt to future climate change.

Adaptation is not without cost. But adaptive strategies for technological and behavioral adaptation that are economically justifiable offer an opportunity to reduce the vulnerability of sensitive human and ecological systems to the effects of climate change and variability (IPCC 1997). Economical adaptive strategies also offer an opportunity to exploit potential opportunities. In many cases, adaptation makes sense whether or not the uncertain effects of climate change are realized.

There will be a regional and demographic texture to the beneficial and adverse effects of climate change on human and ecological systems. A sound understanding of the distribution of potential impacts across different regions and populations is required to target appropriate investments in adaptive responses. Understanding the mechanisms by which impacts occur is also key to the development of effective adaptation measures.

Uncertainties exist about the efficacy of particular adaptive strategies. Current efforts to cope with the effects of climate variability provide valuable insights into the potential effectiveness of future adaptive responses. Adaptive responses vary in effectiveness, as illustrated by the persistence of preventable deaths due to heat stress in urban areas, even under current climatic conditions. Uncertainties also exist about possible secondary and undesirable effects of adaptation. Potential adverse side effects of particular adaptive responses must also be accounted for to avoid solutions that are worse than the problem.

Scientific investigations can help define the risks and opportunities presented by climate change and variability, and provide an understanding of the potential regional and demographic distribution of these consequences. Technology and behavioral changes offer a wide range of possible adaptive responses. The 9 principles articulated in this paper can help ensure that investments made in adaptation are effective, economical, environmentally friendly, and socially acceptable.

Note. J oel Scheraga is the Program Director of the Global Change Research Program in EPA's Office of Research and Development. Anne Grambsch is a Senior Economist in the Climate and Policy Assessment Division of EPA's Office of Policy. The views expressed are the authors' own and do not represent official EPA policy.

\section{LITERATURE CITED}

Adams RM, Fleming RA, Chang CC, McCarl BA (1995a) A reassessment of the economic effects of global climate change on United States agriculture. Clim Change 30(2): 147-167

Adams RM, McCarl BA, Segerson K, Rosenzweig C, Bryant KJ , Dixon BL, Connor R, Evenson RE, Ojima D (1995b) The economic effects of climate change on United States agriculture. Final report, Electric Power Research Institute, Climate Change Impacts Program, Palo Alto, CA

Bijlsma L (1996) Coastal zones and small islands. In: Watson RT, Zinyowera MC, M oss RH (eds) Climate change 1995: impacts, adaptations and mitigation of climate change: scientific-technical analyses. Cambridge University Press, Cambridge, p 289-324

Blum LN, Bresolin LB, Williams MA (1998) Heat-related illness during extreme weather emergencies. J Am Med Assoc 279(19):1514

Buechley RW, Van Bruggen J , Truppi LE (1972) Heat island = death island? Environ Res 5:85-92

CDC (Centers for Disease Control and Prevention) (1988) M orb M ortal Wkly Rep 47(3):473-476

CDC (Centers for Disease Control and Prevention) (1995) Heat-related mortality - Chicago. Morb Morta Wkly Rep 44:577-579

Chestnut LG, Breffle WS, Smith J B, Kalkstein LS (1998) Analysis of differences in hot-weather-related mortality across 44 United States metropolitan areas. Environ Sci Pol 1:59-70

Eaton J G, McCormick J H, Goodno BE, O'Brien DG, Stefan HG, Hondzo M, Scheller RM (1995) A field informationbased system for estimating fish temperature tolerances. Fisheries, Vol 20, No 4, p 10-18

Everett J T (1996) Fisheries. In: Watson RT, Zinyowera MC, 
Moss RH (eds) Climate change 1995: impacts, adaptations and mitigation of climate change: scientific-technical anaIyses. Cambridge University Press, Cambridge, p 511-537

IPCC (Intergovernmental Panel on Climate Change) (1996a) In: Houghton J T, M eira Filho LG, Callander BA, Harris N, Kattenberg A, Maskell K (eds) Climate change 1995: the science of climate change. Cambridge University Press, Cambridge, p 1-7

IPCC (Intergovernmental Panel on Climate Change) (1996b) In: Watson RT, Zinyowera MC, Moss RH (eds) Climate change 1995: impacts, adaptations and mitigation of climate change: scientific-technical analyses. Cambridge University Press, Cambridge, p 1-18

IPCC (Intergovernmental Panel on Climate Change) (1996c) IPCC second assessment: climate change 1995. UNEP/ WM O. Cambridge University Press, Cambridge, $\mathrm{p} 3$

IPCC (Intergovernmental Panel on Climate Change) (1997) In: Watson RT, Zinyowera MC, Moss RH (eds) The regional impacts of climate change: an assessment of vulnerability. Cambridge University Press, Cambridge, p 253-330

J ones PD (1994) Hemispheric surface air temperature variations: a reanalysis and an update to 1993. J Clim 7: 1794-1802

Kalkstein LS, Greene J S (1997) An evaluation of climate/mortality relationships in large United States cities and the possible impacts of a climate change. Environ Health Perspect 105(1):84-93

Kalkstein LS, Smoyer KE (1993) The impact of climate change on human health: some international implications. Experiencia 49:469-479

Karl TR, Knight RW, Easterling DR, Quayle RG (1996) Indices of climate change for the United States. Bull Am M eteorol Soc 77(2):279-292

Kilbourne EM, Choi K, J ones TS, Thacker SB Field Investigation Team (1982) Risk factors for heat-related heatstroke: a case-control study. J Am Med Assoc 247:3332-3336

Mahlman JD (1997) Uncertainties in projections of humancaused climate warming. Science 278:1416-1417

Manabe S, Wetherald RT (1987) Large-scale changes in soil wetness induced by an increase in carbon dioxide. J Atmos Sci 44:1211-1235

Nashold R, Remington P, Peterson P, J entzen J, Kapella R (1996) Heat-wave-related mortality - Milwaukee, Wisconsin, J uly 1995. M orb M ortal Wkly Rep 45:505-507

NAS (National Academy of Sciences) (1992) Policy implications of greenhouse warming: mitigation, adaptation, and the science base. National Academy Press, Washington, DC

NOAA (National Oceanic and Atmospheric Administration) (1995) J uly 1995 heat wave, natural disaster survey report. United States Department of Commerce, Washington, DC

Oke TR (1973) City size and the urban heat island. Atmos Environ 7:769-779

OTA (Office of Technology Assessment) (1993) Preparing for an uncertain climate. United States Government Printing Office, Washington, DC

Parker DE, Folland CK, Jackson M (1995) Marine surface temperature: observed variations and data requirements. Clim Change 31:559-600

Parry M, Carter T (1998) Climate impact and adaptation assessment, Earthscan Publications Ltd, London

Reilly J (1996) Agriculture in a changing climate: impacts and adaptation. In: Watson RT, Zinyowera M C, M oss RH (eds) Climate change 1995: impacts, adaptations and mitigation of climate change: scientific-technical analyses. Cambridge University Press, Cambridge, p 427-467

Reilly J , Hohmann N, Kane S (1994) Climate change and agricultural trade: who benefits, who loses? Global Environ Change 4(1)24-36

Rosenzweig C, Parry M L, Fischer G (1995) World food supply. In: Strzepek KM , Smith J B (eds) As climate changes: international impacts and implications. Cambridge University Press, Cambridge, p 27-56

Scheraga JD (1998) Climate change, regional impacts and adaptation. In: Mortsch LD, Quon S, Craig L, Mills B, Wrenn $B$ (eds) Adapting to climate change and variability in the Great Lakes-St. Lawrence Basin, Proceedings of a binational symposium. Environment Canada. University of Waterloo Graphics, Waterloo, p 40-51

Semenza J C, Rubin CH, Faltern KH, Selanikio J D, Flanders WD, Howe HL, Wilhelm J L (1996) Risk factors for heatrelated mortality during the July 1995 heat wave in Chicago. N Eng J Med 335:84-90

Shriner DS, Street RB (1997) North America. In: Watson RT, Zinyowera MC, M oss RH (eds) The regional impacts of climate change: an assessment of vulnerability. Cambridge University Press, Cambridge, p 253-330

Smith J B (1997) Setting priorities for adapting to climate change. Global Environ Change 7(3):251-264

Smith J B, Lenhart SS (1996) Climate change adaptation policy options. Clim Res 6:193-201

Smith J B, Carmichael J J, Titus J G (1995) Adaptation policy. In: Strzepek KM , Smith J B (eds) As climate changes: international impacts and implications. Cambridge University Press, Cambridge, p 201-210

Titus J G (1986) Greenhouse effect, sea level rise, and coastal zone management. Coastal Zone M anage J 14(3):147-171

Titus J G (1998) Rising sea, coastal erosion, and the takings clause: how to save wetlands and beaches without hurting property owners. Md Law Rev 57:1279-1399

Titus J G, Park RA, Leatherman S, Weggel R, Greene MS, Treehan M, Brown S, Gaunt C, Yohe G (1991) Greenhouse effect and sea level rise: the cost of holding back the sea. Coastal Manage 19:171-204

Tol RSJ , Fankhauser S, Smith J B (1998) The scope for adaptation to climate change: what can we learn from the impact literature? Global Environ Change 8(2):109-123

U.S. Department of Interior National Survey of Fishing, Hunting, and Wildlife-Associated Recreation, Washington, DC, 1997

U.S. EPA (U.S. Environmental Protection Agency) (1989) The potential effects of global climate change on the United States. U.S. Environmental Protection Agency, Washing ton, DC

U.S. EPA (U.S. Environmental Protection Agency) (1995a) The probability of sea level rise. Office of Policy, Planning, and Evaluation, Washington, DC, EPA 230-R-95-008

U.S. EPA (U.S. Environmental Protection Agency) (1995b) Ecological impacts from climate change: an economic analysis of freshwater recreational fishing. Office of Policy, Planning, and Evaluation, Washington, DC, EPA 220-R-95-004

WHO (World Health Organization) (1996) Climate change and human health. MCMichael AJ, Haines A, Sloof R, Kovats S (eds) World Health Organization, Geneva 